\title{
Sonographic estimation of foetal weight versus actual birth weight at term
}

\author{
Akinshola A. Ero-Phillips ${ }^{1}$, Faosat O. Jinadu' ${ }^{1 *}$, Abimbola T. Ottun ${ }^{2}$, \\ Ayokunle M. Olumodeji ${ }^{2}$
}

\begin{abstract}
${ }^{1}$ Department of Radiology, ${ }^{2}$ Department of Obstetrics and Gynaecology, Lagos State University Teaching Hospital, Lagos, Ikeja, Nigeria
\end{abstract}

Received: 06 April 2021

Accepted: 19 April 2021

\section{*Correspondence:}

Dr. Faosat O. Jinadu,

E-mail: jinadufaosat@gmail.com

Copyright: ( $)$ the author(s), publisher and licensee Medip Academy. This is an open-access article distributed under the terms of the Creative Commons Attribution Non-Commercial License, which permits unrestricted non-commercial use, distribution, and reproduction in any medium, provided the original work is properly cited.

\begin{abstract}
Background: Estimated foetal weight is very critical to decision making in the management of pregnant women. It is therefore important to evaluate the accuracy of ultrasound estimated foetal weight (USEFW) at term in our environment. We compared ultrasound estimated foetal weight at term with the actual foetal birth weight at delivery.

Methods: This was a prospective, comparative cross-sectional study at the Lagos State University Teaching Hospital over a 6-month period. Four hundred and five pregnant women with normal singleton pregnancy, who had sonographic estimation of foetal weight at term, using the Hadlock IV formula, were followed up and had their actual birth weight (ABW) determined at delivery. Accuracy was determined by proportion of estimates within $10 \%$ of actual birth weight and mean absolute percentage error (MAPE). The $\mathrm{p}<0.05$ was considered significant at $95 \%$ confidence interval.

Results: The prevalence of macrosomia was $10.3 \%$. At $10 \%$ margin of error, ultrasound accurately estimated the weights of $73.3 \%$ of babies. The mean USEFW was $3559.89 \pm 316.9 \mathrm{~g}$ and mean ABW was $3477.42 \pm 422.9 \mathrm{~g}$ with a mean difference of $82.44 \mathrm{~g}(\mathrm{p}<0.001)$ and MAPE of 7.11. There was positive correlation $(\mathrm{r}=0.669)$ between the EFW and ABW ( $p<0.001$ ). The USEFW had a sensitivity of $66.7 \%$, specificity of $91.5 \%$, positive predictive value of $47.5 \%$ and negative predictive value of $96.0 \%$ in predicting macrosomia.

Conclusions: Ultrasound estimation of foetal weight at term is reliably accurate in predicting actual birth weight in south-western Nigeria.
\end{abstract}

Keywords: Birth-weight, Foetal weight, Ultrasound estimated foetal weight

\section{INTRODUCTION}

Assessment of foetal weight is vital in routine antenatal management especially in high risk pregnancies where growth monitoring is of utmost importance. ${ }^{1}$ Accurate estimation of term foetal weight can help the obstetrician in decision making regarding the baby's survival outside the uterus. ${ }^{1}$ Birth weight remains the principal variable with the most impact on survival of the neonate. ${ }^{2}$ Globally an estimated $16 \%$ of live born infants have low birth weight, a condition associated with high perinatal morbidity and mortality. ${ }^{3}$ An average estimate of perinatal mortality rate in Nigeria is about 130 per $1000 .^{4,5}$ Such high rate of perinatal mortality is a major cause of concern as is in other developing countries. ${ }^{4}$ Large for gestational age babies are also at increased risk of neonatal complications. ${ }^{6}$ Adequate knowledge of the weight of the foetus in-utero is thus of particular importance in the management of pregnancy, labour and delivery, affording the obstetrician and neonatologist ample information and time to anticipate and prevent foetal weight-related maternal and perinatal morbidity and mortality. ${ }^{3}$ 
The two main methods for predicting foetal birth weight in current obstetrics practice are clinical and ultrasonographic. ${ }^{6}$ The ultrasound method is generally a better predictor of the actual birth weight than the clinical method, and thus should be used in estimating the actual birth weight when accessible. ${ }^{1,7}$ Modern sonographic algorithms that currently exist are generally comparable in terms of overall accuracy in predicting birth weight. ${ }^{8,9}$ This study assessed the accuracy of ultrasound estimated foetal weight by comparing ultrasound estimated foetal weight at term with their actual foetal birth weight at delivery, using the Hadlock IV formula.

\section{METHODS}

This was a hospital-based, prospective, comparative crosssectional study in the Lagos State University Teaching Hospital over a 6-month period (September 2017 to February 2018). Four hundred and five consecutively consenting pregnant women with singleton pregnancy between gestational ages of 37 weeks and 42 weeks, with either an ultrasound estimated gestational age before 13 weeks or known last menstrual period, for dating of pregnancy, were recruited for the study. Women with preterm pregnancy, high risk pregnancy, active phase of labour, multiple gestation and foetal congenital anomaly were excluded from the study.

Relevant socio-demographic data were obtained with the aid of a proforma specially designed for the study. All consenting pregnant women had an obstetric ultrasound scan performed within 14 days of the expected date of delivery (40 weeks gestational age) to exclude congenital anomaly, ascertain foetal well-being and determine the estimated foetal weight (EFW) using the Hadlock IV formula. Pregnant women who did not deliver within 14 days of their obstetric ultrasound scan repeated their scan to re-estimate foetal weight. Women initially recruited who remained undelivered at 42 weeks and beyond were exited from the study.

All sonographic foetal biometric examinations in the radiology unit were performed trans-abdominally by experienced consultant radiologist using a $3.5 \mathrm{MHz}$ curvilinear transducer of high-quality ultrasound systems (Mindray Z5; Mindray Bio-Medical Electronics Co. Ltd. Shenzhen). The average estimated foetal weight was calculated using the Hadlock IV formula below incorporated in the ultrasound machine. ${ }^{10}$

$$
\log 10 E F W=1.335-0.0034(A C)(F L)+
$$$$
0.0316(B P D)+0.0457(A C)+0.1623(F L)
$$

The bi-parietal diameter (BPD) was measured from the proximal echo of the foetal skull to the proximal edge of the deep border (outer-inner) at the level of the cavum septi pellucidi. The head circumference (HC) was measured as an ellipse around the perimeter of the fetal skull. ${ }^{11}$ The abdominal circumference (AC) was measured in the transverse plane of the fetal abdomen at the level of the umbilical vein in the anterior third and the stomach bubble in the same plane; measurements are taken around the perimeter. ${ }^{12}$ The femur length (FL) was measured in a view in which the full femoral diaphysis was seen and was taken from one end of the diaphysis to the other, not including the distal femoral epiphysis. 13

At delivery the actual birth weight (ABW) was determined within 30 minutes of delivery using a digital birth weighing scale (SECALENA model 354 by SecaGmBH and co 22089 Hamburg Germany) and recorded to the nearest $10 \mathrm{~g}$.

The data obtained from the study proforma, ultrasound scan EFW and ABW measurements were statistically analysed using Statistical Package for Social Sciences, version 20.0 (SPSS v20.0) Chicago, Illinois. Descriptive statistics were calculated for continuous variables. Percentages and proportions were determined for categorical variables. Student's t-test and chi square were used to compare variables. Measures of accuracy evaluated in the statistical analysis include mean absolute percentage error, and the proportion of estimates within $5 \%$ and $10 \%$ of actual birth weight. The spearman correlation between the estimated foetal weight and the actual weight was also determined. P-value less than 0.05 was considered to be statistically significant (confidence level $=95 \%$ ). Ethical approval was obtained from the Health Research and Ethics Committee of the Lagos State University Teaching Hospital.

\section{RESULTS}

A total of 405 pregnant women with normal singleton pregnancies at term were recruited and scanned within two weeks of delivery.

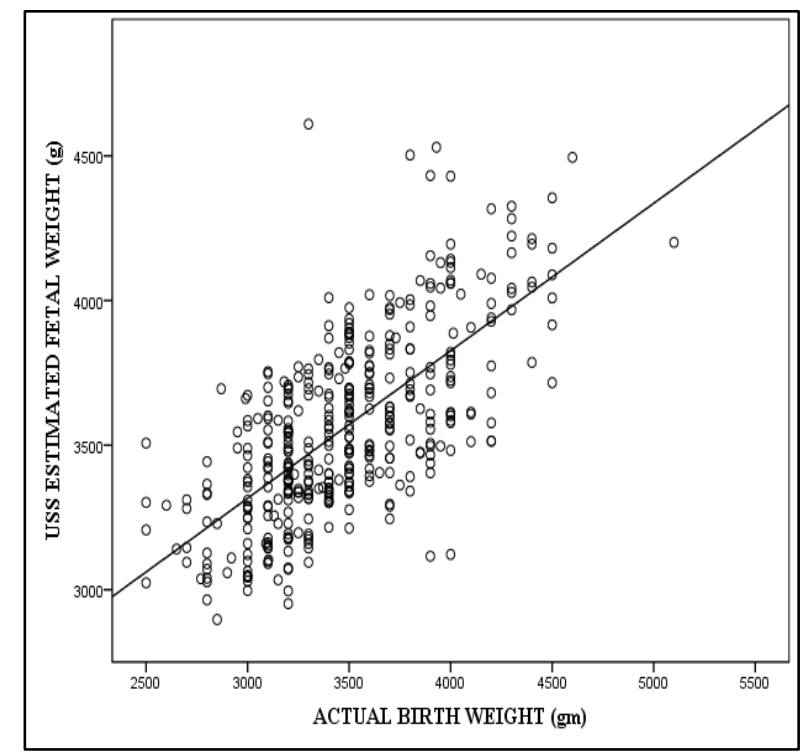

Spearman correlation $=0.669, \mathrm{p}=<0.001 *$

Figure 1: Scatter plot showing the correlation between actual birth weight and ultrasound estimated foetal weight. 
The mean maternal age was $30.98 \pm 4.5 y e a r s, 176(43.5 \%)$ of the women were overweight, 174 (43\%) were primigravidae with median IQR of 2 (Q1-Q3=0.0-3.0), $225(55.6 \%)$ had spontaneous vaginal delivery and $52.8 \%$ (214) were delivered of male infants (Table 1). The mean gestational age at delivery was $38.48 \pm 0.9$ weeks (Table 1 ). None of the babies had low birth weight $(<2500 \mathrm{~g})$ at birth and the prevalence of macrosomia $(\geq 4000 \mathrm{~g})$ in the study was $14.6 \%$ (Table 1).

Table 1: Socio-demographic and clinical characteristics of the study population.

\begin{tabular}{|c|c|}
\hline & Frequency $n=405(\%)$ \\
\hline \multicolumn{2}{|l|}{ Maternal age, years } \\
\hline$\leq 25$ & $48(11.9)$ \\
\hline $26-30$ & $148(36.5)$ \\
\hline $31-35$ & $136(33.6)$ \\
\hline \multirow{2}{*}{$\geq 36$} & $73(18.0)$ \\
\hline & Frequency $n=405(\%)$ \\
\hline Mean (SD) & $30.98 \pm 4.5$ \\
\hline \multicolumn{2}{|l|}{ BMI $\left(\mathrm{kg} / \mathrm{m}^{2}\right)$} \\
\hline Normal & $120(29.6)$ \\
\hline Overweight & $176(43.5)$ \\
\hline Class I obesity & $86(21.3)$ \\
\hline Class II obesity & $18(4.4)$ \\
\hline Class III obesity & $5(1.2)$ \\
\hline \multicolumn{2}{|l|}{ Parity } \\
\hline None & $182(44.9)$ \\
\hline 1 & $113(27.9)$ \\
\hline 2 & $65(16.1)$ \\
\hline$\geq 3$ & $45(11.1)$ \\
\hline Median (IQR) & $1.0(0.0-2.0)$ \\
\hline \multicolumn{2}{|l|}{ EGA at Birth, weeks } \\
\hline 37 & $60(14.8)$ \\
\hline 38 & $157(38.8)$ \\
\hline 39 & $127(31.4)$ \\
\hline 40 & $54(13.3)$ \\
\hline 41 & $7(1.7)$ \\
\hline Mean \pm SD & $38.48 \pm 0.9$ \\
\hline \multicolumn{2}{|l|}{ Mode of delivery } \\
\hline Spontaneous vaginal delivery & $225(55.6)$ \\
\hline Caesarean section & $180(44.4)$ \\
\hline \multicolumn{2}{|l|}{ Baby's gender } \\
\hline Male & $214(2.8)$ \\
\hline Female & $191(47.2)$ \\
\hline \multicolumn{2}{|l|}{ Actual Birth Weight, grammes } \\
\hline Low birth weight & $0(0.00)$ \\
\hline Normal birth weight & $363(89.6)$ \\
\hline Macrosomia & $42(10.4)$ \\
\hline
\end{tabular}

Table 2: Comparison of error of estimation of normal weight and macrosomic babies on ultrasound.

\begin{tabular}{|c|c|c|c|c|}
\hline & $\begin{array}{l}\text { Total } \\
\mathrm{N}=405(\%)\end{array}$ & $\begin{array}{l}\text { Normal } \\
n=346(\%)\end{array}$ & $\begin{array}{l}\text { Macrosomic } \\
\mathrm{n}=59(\%)\end{array}$ & P value* \\
\hline \multicolumn{5}{|l|}{$5 \%$ margin of error } \\
\hline Accurate estimation & $183(45.2)$ & $160(46.2) 0$ & $23(39.0)$ & \multirow{4}{*}{$<0.001$} \\
\hline Inaccurate estimation & $222(54.8)$ & $186(53.8)$ & $36(61.0)$ & \\
\hline Underestimation & $152(37.5)$ & $151(43.7)$ & $1(1.6)$ & \\
\hline Overestimation & $70(17.3)$ & $35(10.1)$ & $35(59.3)$ & \\
\hline
\end{tabular}

Continued. 


\begin{tabular}{|c|c|c|c|c|}
\hline & $\begin{array}{l}\text { Total } \\
\mathrm{N}=405(\%)\end{array}$ & $\begin{array}{l}\text { Normal } \\
n=346(\%)\end{array}$ & $\begin{array}{l}\text { Macrosomic } \\
\mathrm{n}=59(\%)\end{array}$ & P value* \\
\hline \multicolumn{5}{|l|}{$10 \%$ margin of error } \\
\hline Accurate estimation & $297(73.3)$ & $259(74.9)$ & $38(64.4)$ & \multirow{4}{*}{$<0.001$} \\
\hline Inacurate estimation & $108(26.7)$ & $87(25.1)$ & $21(35.6)$ & \\
\hline Underestimation & $72(17.8)$ & $72(20.8)$ & $0(0.0)$ & \\
\hline Overestimation & $36(8.9)$ & $15(4.3)$ & $21(35.6)$ & \\
\hline
\end{tabular}

*- Chi square $(X)^{2}$ applied, n-number of babies, Macrosomic-Babies weighing $\geq 4 \mathrm{~kg}$

Table 3: Comparison of mean ultrasound EFW and ABW.

\begin{tabular}{|lllll|} 
Parameters & $\begin{array}{l}\text { Mean } \pm \\
\text { SD }\end{array}$ & Range & $\begin{array}{l}\text { Mean } \\
\text { difference }\end{array}$ & $\begin{array}{l}\text { P } \\
\text { value* }\end{array}$ \\
\cline { 1 - 2 } $\begin{array}{l}\text { Ultrasound } \\
\text { EFW }\end{array}$ & $\begin{array}{l}3559.86 \\
\pm 316.9\end{array}$ & $\begin{array}{l}2897- \\
4610\end{array}$ & & $<\mathbf{0 . 0 0 1}$ \\
\hline $\begin{array}{lllll}\text { Actual } \\
\text { birth }\end{array}$ & 3477.42 & $2500-$ & 82.440 & \\
weight & \pm 422.9 & 5100 & & $<\mathbf{0 . 0 0 1}$ \\
\hline
\end{tabular}

Mean Absolute percentage error $=7.11$

*- Student t-test applied, g-gramme, EFW - Estimated foetal weight, ABW-Actual birth weight

Table 4: Accuracy of ultrasound estimated foetal weight in identifying macrosomic babies.

\begin{tabular}{|c|c|c|}
\hline & \multicolumn{2}{|c|}{ Actual birth weight } \\
\hline & $\begin{array}{l}\text { Macrosomic } \\
n=42(\%)\end{array}$ & $\begin{array}{l}\text { Normal } \\
n=363(\%)\end{array}$ \\
\hline \multicolumn{3}{|l|}{ Ultrasound EFW } \\
\hline $\begin{array}{l}\text { Macrosomic } n=59 \\
(\%)\end{array}$ & $28(66.7)(47.5)$ & $\begin{array}{l}31(8.5) \\
(52.5)\end{array}$ \\
\hline Normal $n=346(\%)$ & $14(33.3)(4.0)$ & $\begin{array}{l}332(91.5) \\
(96.0)\end{array}$ \\
\hline
\end{tabular}

(\%) - Column percentage, [\%] - Row percentage, $\mathrm{n}$ - number of foetuses/babies. Positive Predictive Value $=47.5 \%$, Negative Predictive Value $=96.0 \%$, Sensitivity $=66.7 \%$, Specificity $=$ $91.5 \%$

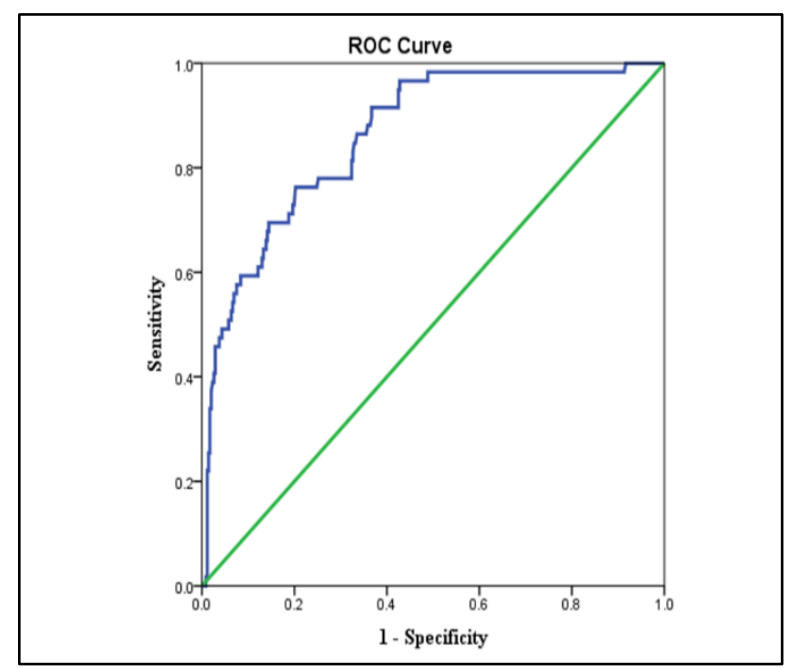

Figure 2: ROC curve showing ultrasound EFW as a predictor of the $\mathrm{ABW}$.
At $10 \%$ margin of error, of the total number of babies delivered ultrasound accurately estimated the weights of 297 babies $(73.3 \%), 259(74.9 \%)$ of which were normal weight and $38(64.4 \%)$ were macrosomic (Table 2). No macrosomic baby was underestimated (Table 2). At $5 \%$ margin of error, 151 (43.7\%) of normal weight babies were underestimated and $35(59.3 \%)$ of macrosomic babies were overestimated (Table 2). When the accuracy of ultrasound at estimating normal weight babies was compared with macrosomic babies, at both 5\% and $10 \%$ margin of error the differences were statistically significant $(\mathrm{p}<0.001)$ (Table 2$)$. Cohen kappa value was $67.2 \%$.

The mean ultrasound estimated foetal weight (USEFW) was $3559.89 \pm 316.9 \mathrm{~g}$ and mean actual birth weight (ABW) was $3477.42 \pm 422.9 \mathrm{~g}$ (Table 3).

The mean difference between the USEFW and ABW was $82.44 \mathrm{~g}$ with a significant $\mathrm{p}<0.001$ and mean absolute percentage error of 7.11 (Table 3). There was positive correlation $(\mathrm{r}=0.669)$ between the $\mathrm{EFW}$ and $\mathrm{ABW}$ $(\mathrm{p}<0.001)$ (Figure 1). Figure 2 is a ROC curve showing how reliable ultrasound estimated foetal weight at term is at predicting the actual birth weight. The USEFW had a sensitivity of $66.7 \%$, specificity of $91.5 \%$ and positive predictive value of $47.5 \%$ and negative predictive value of $96.0 \%$ in predicting macrosomia (Table 4).

\section{DISCUSSION}

The prevalence of macrosomia at birth in this study was $10.3 \%$. This is similar to the findings of Iyoke et al in Enugu, who reported a prevalence rate of $9.3 \%$, Mai et al in West Algeria of a $10.19 \%$ and Ashrafgan et al in Iran of $9.0 \% .^{14-16}$ It is however higher than reports of Abudu et al in Lagos with a prevalence of $4.9 \%$, Kanamu et al in Aba with $2.5 \%$ and Abena et al in Cameroun with prevalence of $6.41 \% .{ }^{17-19}$ These may largely be due to the different socio-economic circumstances of the participants and variation in study protocols as only normal pregnant women were recruited in our study.

The mean gestational age of delivery in this study was 38.48 weeks; this is similar to 38.6 weeks reported by Shittu et al in Ile-Ife. ${ }^{8}$ It is however different from the findings of 35.8 weeks by Yau et al in Hong Kong and 37.3 weeks by Predanic et al in New York in related studies. ${ }^{20,21}$ These differences may be due to inclusion of preterm infants in these studies by Yau et al and Predanic et al. 
The accuracy within $5 \%$ and $10 \%$ margin of error in this study was $45.2 \%$ and $73.3 \%$ respectively. This is comparable to the findings of Shittu et al in Ile-Ife, who reported $69 \%$ (10\% degree of accuracy) and Njoku et al in Calabar, who reported $72 \%$ within $10 \%$ of ABW, Predanic et al in New York, with $40.3 \%$ and $73.6 \%$ within 5 and $10 \%$ of ABW respectively, Colman et al in New Zealand, with $75 \%$ within $10 \%$ of ABW, Benaceraf et al in Boston, with $42 \%$ and $74 \%$ within 5 and $10 \%$ of ABW respectively. ${ }^{8,21-24}$ It is however lower than the findings of Harlev et al in Israel, with $76 \%$ within $10 \%$ of ABW, Yau et al in Hong Kong, with $79.3 \%$ within $10 \%$ of ABW and higher than those of Bajracharya et al in Kathmandu, with $60 \%$ within $10 \%$ of ABW, Japarath et al in Thailand, with $65.3 \%$ within $10 \%$ of $\mathrm{ABW}$ and Bakshi et al in Dhaka, with $57.3 \%$ within $10 \%$ of $\mathrm{ABW} .^{20,2528}$ These variations may reflect population differences as well as interobserver differences associated with varying degrees of proficiency by sonologists used in the various studies.

In our study the mean USEFW was $3.559 .87 \mathrm{~g}$, mean ABW was $3477.42 \mathrm{~g}$ and the mean difference was 82.440 $\mathrm{g}(\mathrm{p}<0.001)$. This difference is probably explained by the fact that measurements are based on a formula that use two or more variables and assumes a uniform relationship between two dimensional areas derived from those diameters and volume which is then translated into weight. ${ }^{29}$ This uniform relationship may not actually exist because foetuses are not perfectly globular structures. ${ }^{29}$ Secondly, the weights of foetuses in the study were not estimated during labour or immediately prior to caesarean delivery. The mean absolute percentage error (MAPE) in our study is $7.11 \%$. This is similar to that of Colman et al in New Zealand, with a MAPE of 7.0 and better than those of Shittu et al in Ile-Ife, with a MAPE of $9.9 \%$ and Njoku et al in Calabar, with a MAPE of $9.04 \% .^{8,22,23}$ It is however higher than that of Yau et al in Hong Kong, with a MAPE of $5.89 \% .^{20}$ This result is however consistent with what has been previously published that the MAPE for ultrasound estimated foetal weight varies between $6-12 \%$ of ABW. ${ }^{27}$ Ultrasound estimated foetal weight had good positive correlation with the actual birth weight.

Our study revealed sensitivity and specificity of USEFW, using Hadlock IV formula, in identifying macrosomic babies as $66.7 \%$ and $91.5 \%$ respectively. This is similar to the findings of Njoku et al with sensitivity and specificity of $69.4 \%$ and $92.7 \%$, Benaceraf et al in Boston, with $65 \%$ and $90 \%$ and Sekor et al in Brisbane, with $60 \%$ and $95.6 \%$ respectively. ${ }^{22,24,30}$ It is however different from the findings of Yao et al in Chinese Han population, with $48.1 \%$ and $97.1 \%$, Noumi et al in Brooklyn, with 50 and $97 \%$ respectively with better specificity. These differences may be related to the different sonographers used in the studies. $^{31,32}$

\section{CONCLUSION}

Ultrasound estimation of foetal weight at term is reliable in predicting actual birth weight in south-western Nigeria.
Funding: No funding sources

Conflict of interest: None declared

Ethical approval: The study was approved by the Institutional Ethics Committee

\section{REFERENCES}

1. Ugwu EO, Udealor PC, Dim CC, Obi SN, Ozumba $\mathrm{BC}$, Okeke DO, et al. Accuracy of clinical and ultrasound estimation of foetal weight in predicting actual birth weight in Enugu, S Eastern Nigeria. Niger J clin pract. 2014;17(3):270-275.

2. Titapant V, Chawanpaiboon S, Mingmipatanakul KA. Comparison of clinical and ultrasound estimation of foetal weight. J Med Associ Thai. 2001;84:1251-7.

3. Diejomaoh FM. Perinatal and maternal mortality; In: Text book of obstetrics and gynaecology for medical student, Agboola A, editors. Volume 2, Lagos: University Services Educational Publishers, Lagos, Nigeria, First Edition, 1988;304-14.

4. Suleiman MB, Mokuolu OA. Perinatal Mortality in a Northwestern Nigerian City: A Wake up Call. Front Pediatr. 2014;2:105.

5. Nwokoro UU, Dahiru T, Olorukooba A, Daam CK, Waziri HS, Adebowale A et al. Determinants of perinatal mortality in public secondary health facilities, Abuja Municipal Area Council, Federal Capital Territory, Abuja, Nigeria. Pan African Medical Journal. 2020;37:114.

6. Fasubaa OB, Faleyimu BL, Ogunniyi SO. Perinatal outcome of macrosomic babies. Nig $\mathbf{J}$ Med.1991;1:61-2.

7. Peregrine E, O'Brien P, Jauniaux E. Clinical and ultrasound estimation of birth weight prior to induction of labor at term. Ultrasound Obstet Gynecol. 2007;29(3):304-9.

8. Shittu AS, Kuti O, Orji EO. Clinical versus sonographic estimation of foetal weight in southwest Nigeria. J Health Popul Nutr. 2007;25(1):14-23.

9. Esinler D, Bircan O, Esin S, Sahin EG, Kandemir O, Yalvac S. Finding the best formula to predict the fetal weight: comparison of 18 formulas. Gynecol Obstet Invest. 2015;80(2):78-84.

10. Hadlock FP, Harrist RB, Martinez-Poyer J. In utero analysis of fetal growth: a sonographic weight standard. Radiology. 1991;181:129-133.

11. Hadlock FP, Deter RL, Harrist RB, Park SK. Fetal biparietal diameter: rational choice of plane of section for sonographic measurement. AJR Am J Roentgenol. 1982;138:871-874.

12. Hadlock FP, Deter RL, Harrist RB, Park SK. Fetal abdominal circumference as a predictor of menstrual age. AJR Am J Roentgenol. 1982;139:367-370.

13. Jeanty $P$, Kirkpatrick C, Dramaix-Wilmet $M$, Struyven J. Ultrasonic evaluation of fetal limb growth. Radiology. 1981;140:165-168.

14. Iyoke CA, Lawani OL, Ugwu GO, Ezugwu FO, Uchechukwu GC. Yearly trends in foetal microsomia among hospital births in Enugu, South-East Nigeria. 
American journal of clinical medicine Research. 2014; 79-83.

15. Mai A H, Abbasia D. The Prevalence of Foetal Macrosomia at the Specialised Hospital of Gynaecology and Obstetrics in Sidi Bel Abbes (West of Algeria). Journal of Food Nutrition and Food sciences. $4: 272$

16. Ashrafgan J T, Naderi T, Eshrati B, Babapoor N. Accuracy of Ultrasound, Clinical and maternal estimates of Birth weight in Term women At Kerman, Islamic Republic of Iran. Eastern Mediterranean Health Journal. 2010;16:313-317.

17. Abudu OO, Awonuga AO. Foetal macrosomia and pregnancy outcome in Lagos. International journal of gynaecology and obstetrics. 1989;28(3):257-262.

18. Kanamu C I, Onwere S, Chigbu B. Foetal Macrosomia in African Women, a Study of 249 Cases. Arch.\Gynecol Obstet. 2009;279(857).

19. Abena OM , Shasha VW, Fodjo I, Bonongkaho F, Mbede I, Kamdom M I. Foetal Macrosomia In Cameroun: Prevalence, Risk Factors and Complications. W Afr J of Med. 1995;14(4):249-254.

20. Yau PK, Sin WK, Lee HC, Au-Yeung KC. Accuracy of ultrasound estimation of foetal weight by Obstetrics and Gynaecology residents and maternal-foetal medicine sub specialist. Hong Kong J Gynaecol Obstet Midwifery. 2013;13(1):27-32.

21. Predanic M, Cho A, Ingrid F. Ultrasonographic estimation of foetal weight-Acquiring accuracy in Residency. J Ultrasound Med. 2002;21:495-500.

22. Njoku CU, Emechebe CE, Odusolu PU, Abeshi SI, Chukwu CU, Ekabua JA. Determination of accuracy of foetal weight using ultrasound and clinical foetal weight estimations in Calabar, South-South, Nigeria. International Scholarly Research Notices. 2014;2014.

23. Colman A, Dushyant M, Hutton J, Tuohy J. Reliability of Ultrasound Estimated Foetal Weight in singleton Pregnancies. N Z Med J. 2006;119(2141):1211.

24. Benacerraf BR, Gelman R, Frigoletto jr FD. Sonographically Estimated Foetal Weights: Accuracy and Limitation. Am J Obstet Gynaecol. 1998;159(5):1118-1121.

25. Harlev A, Walfisch A, Bar-David J, Hershkovitz R, Friger M, Hallaak M. Maternal Estimation of Foetal Weight as a Complementary Method of foetal weight assessment: A Prospective clinical Trial. J Reprod Med. 2006;51(7):515-520.

26. Bajracharya J, Shrestha NS, Karli C. Accuracy of prediction of birth weight by foetal ultrasound. Kathmandu Univ Med J. 2012;38 (2):74-76.

27. Japarath P, Wiboolphan T. Comparison of the accuracy of foetal weight estimation using clinical and sonographic methods. J Med Assoc Thai. 2004;87(3):1-7.

28. Bakshi L, Begum H A, Khan I, Dey S K, Habib A, Barman K K. Comparative study of clinical and sonographic Estimation of Foetal weight at Term. Mymensingh medical journal. 2015;24(3):572-577.

29. Sarmandal P, Bailey SM, Grant JM. A comparison of three methods of assessing inter-observer variation applied to ultrasonic foetal measurement in third trimester. Br J Obstet Gynaecol. 1989;(96):12611265.

30. Sekar R, Khatun M, Barrett H L, Domcombe G, A Prospective Pilot Study in Assessing the Accuracy of Ultrasound Estimated Foetal Weight Prior to Delivery. ANZJOG. 2016;56(1):49-53.

31. Yao S, Weixiu Z, JIan H, Fansun L. Accuracy of Sonographic Foetal Weight Estimation Prior to Delivery in a Chinese Han Population. Journal of Clinical Ultrasound. 2017;45(8):465-471.

32. Noumi G, Collado-Khoury F, Bombard A, Julliard K, Weiner Z. Clinical and Sonographic Estimation of Fetal weight performed during labour by residents. AJOG. 2004;192(5):1407-1409.

Cite this article as: Ero-Phillips AA, Jinadu FO, Ottun AT, Olumodeji AM. Sonographic estimation of foetal weight versus actual birth weight at term. Int J Reprod Contracept Obstet Gynecol 2021;10:1782-7. 